\title{
Bone mineral density in high-level endurance runners: part A-site-specific characteristics
}

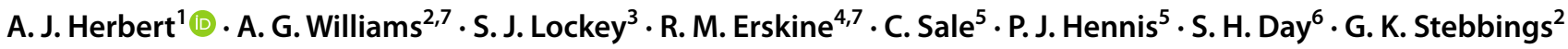

Received: 9 October 2020 / Accepted: 12 August 2021 / Published online: 12 September 2021

(c) The Author(s) 2021, corrected publication 2021

\begin{abstract}
Purpose Physical activity, particularly mechanical loading that results in high-peak force and is multi-directional in nature, increases bone mineral density (BMD). In athletes such as endurance runners, this association is more complex due to other factors such as low energy availability and menstrual dysfunction. Moreover, many studies of athletes have used small sample sizes and/or athletes of varying abilities, making it difficult to compare BMD phenotypes between studies.

Method The primary aim of this study was to compare dual-energy X-ray absorptiometry (DXA) derived bone phenotypes of high-level endurance runners ( 58 women and 45 men) to non-athletes (60 women and 52 men). Our secondary aim was to examine the influence of menstrual irregularities and sporting activity completed during childhood on these bone phenotypes. Results Female runners had higher leg (4\%) but not total body or lumbar spine BMD than female non-athletes. Male runners had lower lumbar spine (9\%) but similar total and leg BMD compared to male non-athletes, suggesting that high levels of site-specific mechanical loading was advantageous for BMD in females only and a potential presence of reduced energy availability in males. Menstrual status in females and the number of sports completed in childhood in males and females had no influence on bone phenotypes within the runners.

Conclusion Given the large variability in BMD in runners and non-athletes, other factors such as variation in genetic makeup alongside mechanical loading probably influence BMD across the adult lifespan.
\end{abstract}

Keywords Bone mineral density $\cdot$ Elite $\cdot$ Marathon $\cdot$ Mechanical loading $\cdot$ Menstruation

Communicated by Philip D Chilibeck.

A. J. Herbert

adam.herbert@bcu.ac.uk

1 School of Health Sciences, Birmingham City University, Birmingham, UK

2 Sports Genomics Laboratory, Department of Sport and Exercise Sciences, Manchester Metropolitan University, Manchester, UK

3 Faculty of Health, Education, Medicine and Social Care, Anglia Ruskin University, Chelmsford, UK

4 School of Sport and Exercise Science, Liverpool John Moores University, Liverpool, UK

5 Musculoskeletal Physiology Research Group, Sport, Health and Performance Enhancement Research Centre, School of Science and Technology, Nottingham Trent University, Nottingham, UK

6 School of Medicine and Clinical Practice, University of Wolverhampton, Wolverhampton, UK

7 Institute of Sport, Exercise and Health, University College London, London, UK

Abbreviations
$\begin{array}{ll}\text { BPAQ } & \text { Bone Physical Activity Questionnaire } \\ \text { BMD } & \text { Bone mineral density } \\ \text { DXA } & \text { Dual-energy X-ray absorptiometry } \\ \text { MANOVA } & \text { Multiple analysis of variance } \\ \text { MANCOVA } & \text { Multiple analysis of covariance } \\ \text { RED-S } & \text { Relative energy deficiency in sport }\end{array}$

\section{Introduction}

Bone mineral density (BMD) is considered to be the primary predictor of osteoporotic fracture (Cranney et al. 2007) although other factors such as geometry, architecture and collagen properties are important determinants of bone strength (Cheung et al. 2016). BMD may also be important for success in the elite sporting environment due to the potential influence on training, performance and injury (Herbert et al. 2019). Diet, hormones and genetics are all known to influence BMD and contribute to large variability within the phenotype (Pluijm et al. 2001). In addition, mechanical 
loading experienced during regular physical activity influences BMD, with load-bearing, high-impact sports associated with increased strain rates, higher peak-force loading and higher BMD (Andreoli et al. 2001). However, the influence of mechanical loading on BMD in endurance athletes is more complex.

Whilst higher leg BMD has been reported in male runners in comparison to non-athletes (Stewart and Hannan 2000; Kemmler et al. 2006) across adulthood (Velez et al. 2008), and in female adolescent runners compared to non-athletes at multiple sites (Duncan et al. 2002), some endurance runners may be at risk of low BMD. In endurance runners, low BMD may increase the risk of stress fracture, which can have negative implications for health and performance (Hind et al. 2006; Barrack et al. 2008; Pollock et al. 2010). Excessive training volumes and/or insufficient dietary intake by endurance runners can result in reduced energy availability, which can negatively impact metabolic processes and potentially reduce BMD (Loucks 2007). Hind et al. (2006) showed low lumbar spine BMD (<-1.0 T-score) in $37 \%$ of 44 male runners aged $19-50$ years in comparison with the manufacturer's reference control database (Lunar Prodigy, GE Systems, UK), whilst lower lumbar spine BMD (Z-score of -1.0 to -2.0 ) has also been reported in adolescent and adult female runners (Barrack et al. 2008; Pollock et al. 2010). Lower BMD was more evident in those runners exhibiting menstrual irregularities (Pollock et al. 2010) or where dietary restraint was occurring (Barrack et al. 2008).

Possession of low or lower BMD by some runners in comparison to other runners may be influenced by a number of factors. Low energy availability and/or menstrual dysfunction, for example, may explain why low or lower BMD is particularly evident in some female runners compared to other female runners or non-athletes (Pollock et al. 2010; Scofield and Hecht 2012). Whilst low energy availability is prevalent in endurance runners, detecting and assessing the impact of menstrual dysfunction and/or low energy availability on BMD and other phenotypes is difficult (Heikura et al. 2018).

No studies, to our knowledge, have assessed the impact of sporting activity in childhood on BMD in adulthood in highlevel endurance runners. Physical activity during childhood can play an important role in the attainment of peak BMD in adulthood (Tveit et al. 2013; Weaver et al. 2016), but it is difficult to complete studies that are both longitudinal and valid due to the challenge of obtaining accurate measurement of activity. Thus, the impact of childhood physical activity in populations, such as endurance runners, and the outcome for BMD is still unclear (Herbert et al. 2019).

In comparison to non-athletes, runners typically demonstrate higher site-specific BMD but similar, or lower, total body and non-loading site BMD (e.g. lumbar spine), due to the associated mechanical loading on the lower extremity
(Scofield and Hecht 2012). It is difficult, however, to directly compare and draw conclusions between the majority of studies in this area due to the substantial differences in methodological design. For example, many studies report on varying sample sizes that comprise athletes of differing ability, which is likely to increase the inter-individual variability within the measured phenotype. Some studies do consist of athletes of a similar ability/standard by recruiting only 'national' or 'regional' level athletes, but the definitions of what constitutes national or regional level athletes are not always clear and consistent (Swann et al. 2015). BMD comparisons between these populations is, therefore, difficult due to a probable difference in training load characteristics. Furthermore, most of these studies have been conducted on non-elite athletes (i.e. defined here as those who have not competed at international or national level), with only one study thus far comprising wholly UK elite endurance runners (Pollock et al. 2010).

In sports, where ability/success is based upon time to complete a specific distance, such as endurance running, criteria based upon personal best time (PB) rather than representative level arguably allows for better assessment of athlete calibre, because national representation requires faster running in some countries than others. Utilising a large cohort of high-level endurance runners of similar competitive standard (based on PB), many undertaking similar training volumes and/or intensities, may somewhat alleviate the aforementioned issues arising from loosely defined populations and their potential confounding variables.

The primary aim of this investigation was to compare total body $\left({ }_{\mathrm{T}} \mathrm{BMD}\right)$, leg $\left({ }_{\mathrm{L}} \mathrm{BMD}\right)$ lumbar spine $\mathrm{BMD}$ ( ${ }_{\mathrm{LS}} \mathrm{BMD}$ ), and total-body T-score and Z-score between highlevel endurance runners (selected based upon $\mathrm{PB}$ ) and nonathletes. The secondary aims were to assess the influence of menstrual irregularities and sporting activity during childhood on these bone phenotypes.

\section{Materials and methods}

\section{Participants and participant recruitment}

All experimental procedures were conducted in accordance with the guidelines in the Declaration of Helsinki and were approved by the local Ethics Committee of Manchester Metropolitan University. Participants consisted of 103 high-level Caucasian runners (45 males, 58 females) who competed in events ranging from $3000 \mathrm{~m}$ to marathon distance and 112 ethnically matched individuals (52 males, 60 females), who did not compete in any sport with a major physical fitness component at regional, national or international level, defined as non-athletes. A sub-group of these participants and some of the associated information and protocols have 
been described previously when assessing the impact of body composition on stress fracture incidence (Varley et al. 2021). Specifically, runners were primarily recruited from the London Marathon Expo between 2012 and 2015 as well as national/regional athletic clubs and organisations. The non-athlete group were recruited through mail-outs, posters and word of mouth. Race PB time was verified by official race chip timings through individual race result websites, the power of 10 (http://www.thepowerof10.info/) and/or the International Association of Athletics Federations (IAAF) (https://www.iaaf.org/home). Runners were included if they had completed at least one official distance event $\geq 3000 \mathrm{~m}$ in a time faster than a predetermined threshold (Table 1). The predetermined threshold time for each distance was chosen to ensure all runners placed in at least the top 600 in the UK rankings for a calendar year based on the years 2012-2017. Average weekly running distance ranged from 24 to $175 \mathrm{~km}$ and training hours per week ranged from 8 to $18 \mathrm{~h}$.

\section{Protocol}

All runners completed a questionnaire detailing geographic ancestry, performance, training practices and injury, as well as sporting history via an adapted version of the Bone Physical Activity Questionnaire (BPAQ) (Weeks and Beck 2008). This allowed initial assessment of running competition standard and assessed the type and number of sporting activities undertaken in childhood. A sporting activity was included if this had been completed for a minimum of 1 year at least twice per week. To assess the influence of sporting history in childhood on bone phenotypes, the past BPAQ (pBPAQ) algorithm was utilised, whereby the effective load stimulus (derived from previous ground reaction force testing) was multiplied against the number of years of participation and the age weighting factor as developed by Weeks and Beck (2008). One male participant was removed from pBPAQ analysis due to discrepancies in the information provided. Female runners also completed a questionnaire detailing menstruation history that allowed identification of those who demonstrate, or have demonstrated, amenorrheic characteristics. Absence of menses until the age of 16 years or

Table 1 Personal best selection criteria for both male and female runners

\begin{tabular}{|c|c|c|}
\hline Distances & Males & Females \\
\hline $3000 \mathrm{~m}$ & $<8 \min 45 \mathrm{~s}$ & $<10 \min 15 \mathrm{~s}$ \\
\hline $5000 \mathrm{~m} / 5 \mathrm{~km}$ road & $<15 \min 45 \mathrm{~s}$ & $<18 \min 45 \mathrm{~s}$ \\
\hline $10,000 \mathrm{~m} / 10 \mathrm{~km}$ road & $<32 \min 45 \mathrm{~s}$ & $<38 \min 45 \mathrm{~s}$ \\
\hline Half marathon & $<74 \min 00 \mathrm{~s}$ & $<88 \min 00 \mathrm{~s}$ \\
\hline Marathon & $<2 \mathrm{~h} 45 \min 00 \mathrm{~s}$ & $<3 \mathrm{~h} 15 \min 00 \mathrm{~s}$ \\
\hline
\end{tabular}

6 months without menstruation were considered potentially amenorrheic (Gordon and Nelson 2003). Non-athletes completed a questionnaire detailing geographic ancestry, general health and physical activity to establish matched geographic ancestry and ensure no history of high-level sport.

All participants completed a whole-body DXA scan (Hologic Discovery W, Vertec Scientific Ltd, UK) to gather $\operatorname{BMD}\left(\mathrm{g} / \mathrm{cm}^{2}\right)$ data by one trained operator following the manufacturer's guidelines. Whole-body and segmental analysis was utilised to obtain ${ }_{\mathrm{T}} \mathrm{BMD},{ }_{\mathrm{L}} \mathrm{BMD}$ and ${ }_{\mathrm{LS}} \mathrm{BMD}$. Totalbody $\mathrm{T}$-score and total-body $\mathrm{Z}$-score were also acquired via the DXA scan and subsequent analysis. Precision of regional analysis for this DXA model has been reported as $1.1 \%$ previously (Ward et al. 2007).

\section{Statistical analysis}

Multiple analysis of variance (MANOVA) was used to compare bone phenotypes $\left({ }_{\mathrm{T}} \mathrm{BMD},{ }_{\mathrm{L}} \mathrm{BMD},{ }_{\mathrm{LS}} \mathrm{BMD}, \mathrm{T}\right.$-score and $\mathrm{Z}$-score) between the female runners and non-athletes and as well as between male runners and their non-athlete counterparts. Coefficient of variation $(\mathrm{CV})$ for ${ }_{\mathrm{T}} \mathrm{BMD},{ }_{\mathrm{L}} \mathrm{BMD}$ and ${ }_{\mathrm{LS}} \mathrm{BMD}$ for both male and female runners as well as their non-athlete counterparts was calculated to assess variability. To account for menstruation, the bone phenotypes of female runners who exhibited signs of amenorrhoea were compared with those who were classed as eumenorrheic via MANOVA. Independent $T$ tests compared age, height and body mass between runners and non-athletes, whilst body mass-adjusted bone phenotype values were analysed via multiple analysis of covariance (MANCOVA). Linear regression was utilised to investigate whether the calculated pBPAQ score was related to bone phenotypes $\left({ }_{T} B M D,{ }_{L} B M-\right.$ Dand $\left.{ }_{L S} B M D\right)$ in adulthood. Alpha was set at 0.05 and data are reported as mean (standard deviation) unless otherwise stated.

\section{Results}

Variability ( $>16 \%$ ) for the three BMD site measures existed for both males and females within runners and non-athletes. Differences in body mass $(P \leq 0.001)$ but not age or height $(P \leq 0.760)$ were present between runners and non-athletes for both males and females (Tables 2 and 3). A significant difference in bone phenotypes between runners and non-athletes was shown for both males and females when adjusted and not adjusted for body mass $(P \leq 0.004)$.

Specifically, ${ }_{\mathrm{LS}} \mathrm{BMD}$ was $9 \%$ lower in male runners than non-athletes $(P=0.004)$ but there were no differences in ${ }_{\mathrm{T}} \mathrm{BMD}(P=0.176),{ }_{\mathrm{L}} \mathrm{BMD}(P=0.963), \mathrm{T}$-score $(P=0.141)$ or $\mathrm{Z}$-score $(P=0.092)$ between these two groups (Table 2$)$. Body-mass adjusted ${ }_{\mathrm{T}} \mathrm{BMD}$ and ${ }_{\mathrm{L}} \mathrm{BMD}$ were $4 \%(P=0.036)$ 
Table 2 Anthropometric characteristics and bone phenotype data in male high-level endurance runners and non-athletes

\begin{tabular}{|c|c|c|c|c|}
\hline & Runners $(n=45)$ & Non-athletes $(n=52)$ & $P$ value & $95 \% \mathrm{CI}$ of the mean difference \\
\hline Age (years) & $36(9)$ & $35(14)$ & 0.565 & -3.360 to 6.118 \\
\hline Height (m) & $1.78(0.06)$ & $1.79(0.07)$ & 0.354 & -0.034 to 0.018 \\
\hline Mass (kg) & $66.9(6.6)$ & $78.0(10.8)$ & $<0.001$ & -14.770 to -7.438 \\
\hline Fat mass $(\mathrm{kg})$ & $11.4(4.3)$ & $17.6(6.5)$ & $<0.001$ & -8.463 to -4.038 \\
\hline Lean mass $(\mathrm{kg})$ & $52.8(4.97)$ & $57.3(6.5)$ & $<0.001$ & -6.776 to -2.124 \\
\hline${ }_{\mathrm{T}} \mathrm{BMD}\left(\mathrm{g} / \mathrm{cm}^{2}\right)$ & $1.285(0.094)$ & $1.315(0.114)$ & 0.176 & -0.072 to 0.013 \\
\hline $\mathrm{CV}(\%)$ & 7.30 & 8.71 & N/A & N/A \\
\hline $\operatorname{Adj}_{T} B M D\left(g / \mathrm{cm}^{2}\right)$ & $1.325(0.014)^{*}$ & $1.281(0.013)$ & 0.036 & $0.003-0.086$ \\
\hline${ }_{\mathrm{L}} \mathrm{BMD}\left(\mathrm{g} / \mathrm{cm}^{2}\right)$ & $1.477(0.108)$ & $1.476(0.132)$ & 0.963 & -0.048 to 0.050 \\
\hline $\mathrm{CV}(\%)$ & 7.33 & 8.93 & N/A & N/A \\
\hline $\operatorname{Adj}_{L} B M D\left(g / \mathrm{cm}^{2}\right)$ & $1.523(0.016)^{*}$ & $1.436(0.015)$ & $<0.001$ & $0.040-0.135$ \\
\hline${ }_{\mathrm{LS}} \mathrm{BMD}\left(\mathrm{g} / \mathrm{cm}^{2}\right)$ & $1.088(0.151)^{*}$ & $1.189(0.181)$ & 0.004 & -0.170 to -0.034 \\
\hline $\mathrm{CV}(\%)$ & 13.84 & 15.25 & N/A & N/A \\
\hline $\operatorname{Adj}_{L S} B M D\left(g / \mathrm{cm}^{2}\right)$ & $1.123(0.026)$ & $1.159(0.024)$ & 0.345 & -0.112 to 0.040 \\
\hline T-score & $0.84(0.88)$ & $1.14(1.07)$ & 0.141 & -0.697 to 0.100 \\
\hline Adj T-score & $1.19(0.14)$ & $0.84(0.13)$ & 0.091 & -0.055 to 0.742 \\
\hline Z-score & $0.82(0.85)$ & $1.13(0.95)$ & 0.092 & -0.678 to 0.052 \\
\hline Adj Z-score & $1.14(0.12)$ & $0.85(0.11)$ & 0.106 & -0.064 to 0.656 \\
\hline${ }_{\mathrm{T}} \mathrm{BMD}$ range & $0.488(1.034-1.522)$ & $0.564(1.067-1.631)$ & N/A & N/A \\
\hline${ }_{\mathrm{L}} \mathrm{BMD}$ range & $0.526(1.193-1.719)$ & $0.749(1.036-1.785)$ & N/A & N/A \\
\hline${ }_{\mathrm{LS}} \mathrm{BMD}$ range & $0.812(0.750-1.560)$ & $0.818(0.830-1.650)$ & N/A & N/A \\
\hline $\mathrm{T}$-score range & $4.60(-1.70-2.90)$ & $5.10(-1.40-3.70)$ & N/A & N/A \\
\hline $\mathrm{Z}$-score range & $4.30(-1.60-2.70)$ & $4.70(-0.90-3.80)$ & N/A & N/A \\
\hline
\end{tabular}

Data are mean (SD) except adjusted values that are mean (SE), range variables that are mean (minimum-maximum) and coefficients of variation $(\mathrm{CV})$ that are percentages

${ }_{T} B M D$ total bone mineral density, ${ }_{L} B M D$ leg bone mineral density, ${ }_{L S} B M D$ lumbar spine bone mineral density, $A d j$ adjusted

*Indicates difference from non-athletes

and 6\% $(P<0.001)$ higher, in male runners than non-athletes but there were no differences in ${ }_{\mathrm{LS}} \mathrm{BMD}(P=0.345)$, T-score $(P=0.091)$ or $\mathrm{Z}$-score $(P=0.106)$ between the two groups (Table 2).

${ }_{\mathrm{L}} \mathrm{BMD}$ was $4 \%$ higher in female runners than non-athletes $(P=0.015)$, but there were no differences in ${ }_{\mathrm{T}} \mathrm{BMD}$ $(P=0.508)$, ${ }_{\text {LS BMD }}(P=0.110)$, T-score $(P=0.478)$ or $\mathrm{Z}$-score $(P=0.847)$ between these two groups (Table 3$)$. Body mass-adjusted ${ }_{\mathrm{T}} \mathrm{BMD}$ was $5 \%(P=0.005)$ and ${ }_{\mathrm{L}} \mathrm{BMD}$ 9\% $(P<0.001)$ higher in female runners compared to nonathletes. Body mass-adjusted T-scores $(P=0.005)$ and $\mathrm{Z}$-scores $(P=0.008)$ were also higher in runners compared to non-athletes but no differences in body mass-adjusted ${ }_{\text {LS }}$ BMD were observed between the two groups $(P=0.893$; Table 3). No differences in ${ }_{\mathrm{T}} \mathrm{BMD}(P=0.293),{ }_{\mathrm{L}} \mathrm{BMD}$ $(P=0.528)$, ${ }_{\text {LS BMD }}(P=0.677)$, T-score $(P=0.295)$ or Z-score $(P=0.740)$ were observed between amenorrheic and eumenorrheic runners (Table 1 in supplementary material).

The calculated pBPAQ score (assessing the type of and number of sports completed in childhood) did not predict ${ }_{\mathrm{T}} \mathrm{BMD},{ }_{\mathrm{L}} \mathrm{BMD}$ or ${ }_{\mathrm{LS}} \mathrm{BMD}$ in adulthood for males $(P=0.832$,
$P=0.962, P=0.864$; Fig. 1; Supplementary Material Fig. 1) or females $(P=0.398, P=0.324, P=0.781$; Fig. 1 ; Supplementary Material Fig. 2).

\section{Discussion}

This investigation is the first to compare bone phenotypes $\left({ }_{\mathrm{T}} \mathrm{BMD},{ }_{\mathrm{L}} \mathrm{BMD},{ }_{\mathrm{LS}} \mathrm{BMD}, \mathrm{T}\right.$-score and Z-score) in high-level endurance runners with a non-athlete group, whilst also assess the impact of childhood sporting activity and menstrual status on BMD within high-level endurance runners.

Higher ${ }_{\mathrm{L}} \mathrm{BMD}$ but not ${ }_{\mathrm{T}}^{\mathrm{BMD} \text { or }}{ }_{\mathrm{LS}} \mathrm{BMD}$ was shown in female runners compared to non-athletes. Specifically, ${ }_{\mathrm{L}} \mathrm{BMD}$ was $0.050 \mathrm{~g} / \mathrm{cm}^{2}$ higher in runners than non-athletes, highlighting the potential effects of site-specific mechanical loading on the lower extremity in endurance runners, which is congruent with some previous research (Brahm et al. 1997; Duncan et al. 2002; Nevill et al. 2003; Scofield and Hecht 2012). Mechanical loading initiates a response in molecular pathways mediating mechanical signalling 
Table 3 Anthropometric characteristics and bone phenotype data in female high-level endurance runners and non-athletes

\begin{tabular}{|c|c|c|c|c|}
\hline & Runners $(n=58)$ & Non-athletes $(n=60)$ & $P$ value & $95 \% \mathrm{CI}$ of the mean difference \\
\hline Age (years) & $34(12)$ & $38(16)$ & 0.235 & -8.287 to 2.053 \\
\hline Height (m) & $1.65(0.06)$ & $1.64(0.06)$ & 0.760 & -0.019 to 0.025 \\
\hline Mass (kg) & $52.9(5.2)$ & $64.7(11.4)$ & $<0.001$ & -14.970 to -8.480 \\
\hline Fat mass $(\mathrm{kg})$ & $12.2(3.2)$ & $22.7(8.1)$ & $<0.001$ & -12.699 to -8.186 \\
\hline Lean mass $(\mathrm{kg})$ & $38.7(3.6)$ & $39.2(5.9)$ & 0.615 & -2.225 to 1.322 \\
\hline${ }_{\mathrm{T}} \mathrm{BMD}\left(\mathrm{g} / \mathrm{cm}^{2}\right)$ & $1.203(0.088)$ & $1.191(0.108)$ & 0.508 & -0.024 to 0.480 \\
\hline $\mathrm{CV}(\%)$ & 7.32 & 9.09 & N/A & N/A \\
\hline $\operatorname{Adj}_{T} B M D\left(g / \mathrm{cm}^{2}\right)$ & $1.226(0.013)^{*}$ & $1.168(0.013)$ & 0.005 & $0.018-0.100$ \\
\hline${ }_{\mathrm{L}} \mathrm{BMD}\left(\mathrm{g} / \mathrm{cm}^{2}\right)$ & $1.285(0.099)^{*}$ & $1.235(0.121)$ & 0.015 & $0.010-0.091$ \\
\hline $\mathrm{CV}(\%)$ & 7.71 & 9.80 & N/A & N/A \\
\hline $\operatorname{Adj}_{L} B M D\left(g / \mathrm{cm}^{2}\right)$ & $1.316(0.015)^{*}$ & $1.205(0.014)$ & $<0.001$ & $0.067-0.155$ \\
\hline${ }_{\mathrm{LS}} \mathrm{BMD}\left(\mathrm{g} / \mathrm{cm}^{2}\right)$ & $1.127(0.149)$ & $1.175(0.178)$ & 0.110 & -0.109 to 0.111 \\
\hline $\mathrm{CV}(\%)$ & 13.19 & 15.16 & N/A & N/A \\
\hline $\operatorname{Adj}_{L S} B M D\left(\mathrm{~g} / \mathrm{cm}^{2}\right)$ & $1.154(0.023)$ & $1.149(0.023)$ & 0.893 & -0.065 to 0.075 \\
\hline T-score & $1.14(1.05)$ & $0.99(1.28)$ & 0.478 & -0.273 to 0.579 \\
\hline Adj T-score & $1.42(0.16)^{*}$ & $0.72(0.16)$ & 0.005 & $0.222-1.182$ \\
\hline Z-score & $1.05(0.90)$ & $1.02(1.15)$ & 0.847 & -0.340 to 0.413 \\
\hline Adj Z-score & $1.33(0.14)^{*}$ & $0.75(0.14)$ & 0.008 & $0.155-0.989$ \\
\hline${ }_{\mathrm{T}} \mathrm{BMD}$ range & $0.350(1.010-1.360)$ & $0.448(0.991-1.439)$ & N/A & N/A \\
\hline${ }_{\mathrm{L}} \mathrm{BMD}$ range & $0.468(1.029-1.497)$ & $0.521(0.993-1.513)$ & N/A & N/A \\
\hline${ }_{\mathrm{LS}} \mathrm{BMD}$ range & $0.760(0.710-1.460)$ & $0.700(0.870-1.570)$ & N/A & N/A \\
\hline $\mathrm{T}$-score range & $4.10(-1.20-2.90)$ & $5.30(-1.50-3.80)$ & N/A & N/A \\
\hline Z-score range & $3.70(-0.90-2.80)$ & $4.30(-0.80-3.50)$ & N/A & N/A \\
\hline
\end{tabular}

Data are mean (SD) except adjusted values that are mean (SE), range variables that are mean (minimum-maximum), and coefficients of variation $(\mathrm{CV})$ that are percentages

${ }_{T} B M D$ total bone mineral density, ${ }_{L} B M D$ leg bone mineral density, ${ }_{L S} B M D$ lumbar spine bone mineral density, $\operatorname{Adj}$ adjusted

*Indicates difference from non-athletes

in bone (e.g. nuclear factor $\mathrm{k}-\mathrm{b} /$ nuclear factor $\mathrm{k}-\mathrm{b}$ ligand/ osteoprotegerin (RANK/RANKL/OPG), Wnt signalling and purinergic signalling pathways), influencing bone formation and resorption (Nakashima et al. 2011). Nevill et al. (2003) reported higher BMD in the legs of female endurance runners in comparison to upper body sites. They concluded that site-specific loading may enhance lower body BMD (via a positive osteogenic effect) at the expense of bone mass of the upper body sites, which may explain why we showed no difference in ${ }_{\mathrm{T}} \mathrm{BMD}$ or ${ }_{\mathrm{LS}} \mathrm{BMD}$ between female runners and non-athletes.

In one of the only other studies to investigate BMD in UK female endurance runners competing at a high-level, Pollock et al. (2010) demonstrated low ${ }_{\mathrm{T}} \mathrm{BMD}$ (Z-score of -1.0 to $-2.0)$ in two $(4.9 \%)$ of the runners only but a median totalbody Z-score of approximately 0.1 for their entire cohort. In the current study, the lowest observed total-body Z-score was -0.9 in the female runners, with a median Z-score of 1.1 for the female runner group, suggesting higher ${ }_{T} B M D$ in the runners we investigated. Sixty-six percent of the runners within this investigation had achieved the PB cutoff criteria for the marathon and at least one other running distance whilst differences in the mean age of the participants between the two studies existed ( $22 \pm 6$ vs $34 \pm 12$ years). Consequently, the impact of age as well as potential differences in the proportion of runners competing across the different running distances $(>800 \mathrm{~m})$ between the two studies and the associated variation in body mass, running training volume and/or strength and resistance-based training practices could have contributed to the differences in findings.

Greater running distance per week has been negatively correlated with BMD (Burrows et al. 2003; Hind et al. 2006), but higher level runners (such as those participating in our investigation) are more likely to undertake resistance/ strength training (Blagrove et al. 2017), which may apply greater amounts of high and multi-directional force to the bone, consequentially benefiting BMD (Nevill et al. 2003). Runners who complete higher volumes of resistance training have higher ${ }_{\mathrm{LS}} \mathrm{BMD}$ that those who may complete lower volumes (Gordon and Nelson 2003), which may explain why we showed no difference in ${ }_{L S} B M D$ between female runners and non-athletes. 
Fig. 1 A Total bone mineral density $\left({ }_{\mathrm{T}} \mathrm{BMD}\right)$; $\mathbf{B}$ leg bone mineral density ( $\left.{ }_{L} B M D\right)$; and C lumbar spine bone mineral density $\left({ }_{L S} B M D\right)$ in male and female high-level endurance runners in relation to their calculated past bone-specific physical activity questionnaire (pBPAQ) score
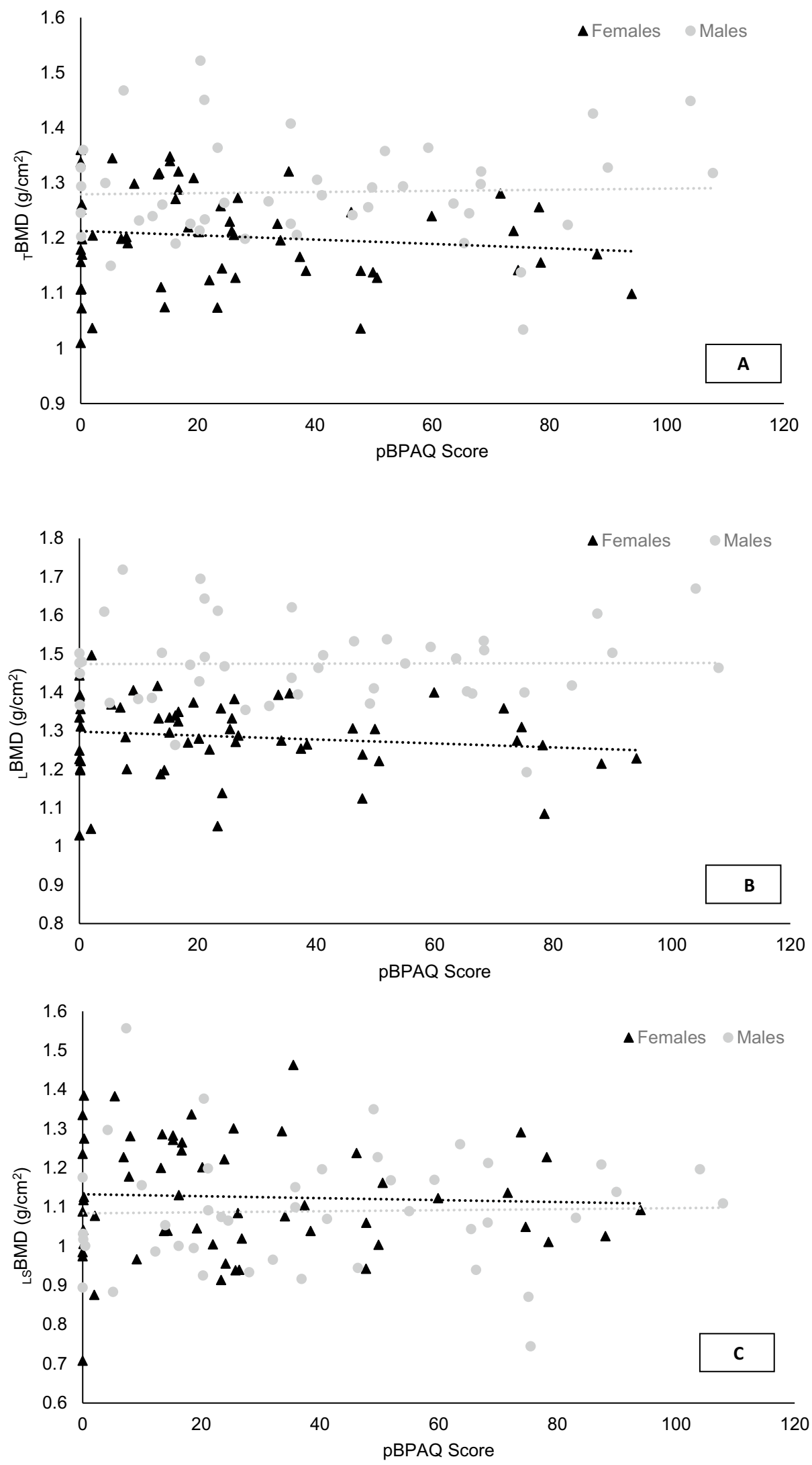
Lower ${ }_{\mathrm{LS}} \mathrm{BMD}$ but no differences in ${ }_{\mathrm{T}} \mathrm{BMD}$ or ${ }_{\mathrm{L}} \mathrm{BMD}$ were present in male runners. It is surprising to report no difference in ${ }_{\mathrm{L}} \mathrm{BMD}$ between the male runners and non-athletes, given the differences observed in the female runners within this study. Previous investigation has also reported ${ }_{\mathrm{L}} \mathrm{BMD}$ can be up to $14 \%$ higher in runners compared to non-athletes (Stewart and Hannan 2000; Kemmler et al. 2006). Kemmler et al. (2006), however, only investigated 20 high-level runners whilst Stewart and Hannan (2000) investigated bone phenotypes in runners with a range of ability, from club to international level, with specific racing distances not stated. Lower ${ }_{\text {LS }}$ BMD in runners compared to non-athletes observed in our investigation is, however, comparable with other research. Lower vertebral (but not tibial or radial) BMD has been shown in male endurance runners completing $92.2 \pm 6.3 \mathrm{~km}$ per week (Bilanin et al. 1989), whilst Hind et al. (2006) and Fredericson et al. (2007) reported low ${ }_{\mathrm{LS}} \mathrm{BMD}$ in comparison to a reference population in male endurance runners. Endurance runners tend to have lower body mass than non-athletes (as shown in this study; Tables 2 and 3) and thus, if all else is equal, lower load will be exerted on these anatomical sites than in nonathletes. In addition, as the lumbar spine is considered a site of relatively less loading during endurance running (Pollock et al. 2010), less mechanical loading will occur here compared to the lower extremity, which might explain why BMD was lower at this site in runners compared to non-athletes, despite no difference in ${ }_{\mathrm{L}} \mathrm{BMD}$ and ${ }_{\mathrm{T}} \mathrm{BMD}$ (Cappozzo 1983; Pollock et al. 2010). However, other factors such as genetic predisposition, hormones and nutritional intake may also influence BMD in endurance runners.

Male runners may be at risk of relative energy deficiency in sport (RED-S), as highlighted in the recent IOC consensus statement (Mountjoy et al. 2018). Low energy availability induced by insufficient dietary intake and/or excessive energy expenditure may increase bone resorption and negatively impact bone metabolic markers, resulting in decreased bone formation, lower bone mass and altered structure (Papageorgiou et al. 2018). The benefits of mechanical loading on BMD, could, therefore, be lost, or reduced, by energy deficiency. Although difficult to assess directly from circulating bone (re)modelling markers, the balance of bone metabolism following repeated training in male endurance runners does not appear to be affected unless an energy deficiency is present, resulting in suppression of bone formation (Papageorgiou et al. 2018). A greater magnitude of loading at the lower extremity and the associated mechanical impact from running may protect against the potentially negative effect of reduced energy availability on BMD and consequently explain why lower ${ }_{\mathrm{LS}} \mathrm{BMD}$ but similar ${ }_{\mathrm{T}} \mathrm{BMD}$ and ${ }_{\mathrm{L}} \mathrm{BMD}$ were shown compared to non-athletes. Energy availability was not measured in this investigation due to the difficulty in accurately measuring this complex phenomenon in such a large sample, so this surmised influence is based upon previous literature. The current methods available to assess energy availability are not without difficultly and consequently, it remains extremely problematic to identify "true" energy availability (Logue et al. 2020).

It is interesting that lower ${ }_{\mathrm{LS}} \mathrm{BMD}$ was only evident in male, and not female, runners in comparison to their nonathlete counterparts. Higher oestrogen may preserve ${ }_{\mathrm{LS}} \mathrm{BMD}$ in female runners. Indeed, studies reporting lower ${ }_{L S} B M D$ in female endurance runners versus non-runners have primarily been in those who may have low energy availability and/or menstrual irregularities (Barrack et al. 2008; Scofield and Hecht 2012). However, we observed no difference in BMD at any site between amenorrheic and eumenorrheic runners (data appeared slightly lower in amenorrheic runners but did not approach statistical significance), suggesting that menstrual status did not affect BMD in our cohort. We assessed potential amenorrhoea and the number of sports completed in childhood via self-report questionnaire. Whilst measurement error exists (Small et al. 2007; Prince et al. 2008), questionnaires are inexpensive and easy to implement in larger cohorts, and widely used (Hoch et al. 2009; Farr et al. 2011; Martin et al. 2017). Other parameters that may influence bone phenotypes, such as smoking history and alcohol intake were not assessed as part of this investigation. Obtaining such information via self-report may not be particularly representative of the truth (Gorber et al. 2009), which in turn impacts the ability to assess or account for these parameters appropriately.

Physical activity during childhood is a key period for bone accretion (Weaver et al. 2016). Therefore, a limited range of physical activities during childhood could have negative implications for adult BMD. Herein, however, we identified no association between pBPAQ score (the type of sport and the number of sports completed in childhood) and any bone phenotype. Consequently, our findings suggest an appropriate volume of physical activity is completed (in childhood) to provide sufficient loading and associated mechanosensory benefit to elevate BMD in most runners.

Of note, we observed higher body-mass adjusted bone phenotypes for both male $\left({ }_{\mathrm{T}} \mathrm{BMD}\right.$ and $\left.{ }_{\mathrm{L}} \mathrm{BMD}\right)$ and female $\left({ }_{\mathrm{T}} \mathrm{BMD},{ }_{\mathrm{L}} \mathrm{BMD}, \mathrm{T}\right.$-score and $\mathrm{Z}$-score) runners in comparison to their non-athlete counterparts. Greater body mass has been shown to positively influence BMD, likely due to the increased load experienced by the bone (Felson et al. 1993). However, when body mass is accounted for, runners demonstrated higher relative BMD, possibly as a result of completing larger volumes of physical activity and benefitting from the associated mechanostransductive effect, than their non-athlete counterparts. The impact of body mass on BMD, however, is influenced by both muscle and fat tissue mass differently as well as the complex relationships 
between these body composition components and mechanical factors (Bierhals et al. 2019).

The large variance in ${ }_{T} \mathrm{BMD},{ }_{\mathrm{L}} \mathrm{BMD}$ and ${ }_{\mathrm{LS}} \mathrm{BMD}$ in both non-athletes and endurance runners is notable. This cannot be attributed solely to age- or physical activityassociated effects on BMD and indicates that other factors such as genetic variation also influence BMD. Heritability of BMD is estimated at $50-85 \%$ (Ralston and Uitterlinden 2010 ) and numerous genes may play a role (Hsu and Kiel 2012; Golchin et al. 2016).

\section{Conclusion}

The findings of this study in high-level endurance runners suggest some may have higher, or similar, BMD at sites experiencing higher mechanical loading but lower BMD at less-loaded sites when compared to non-athletes. These results are consistent with previous research on smaller cohorts (Kemmler et al. 2006), younger populations (Duncan et al. 2002) and in athletes of undefined/lower ability (Hind et al. 2006) but are the first to demonstrate such results in a larger cohort of high-level Caucasian endurance runners, selected based upon PB. Female runners had higher ${ }_{\mathrm{L}} \mathrm{BMD}$ but not ${ }_{\mathrm{T}} \mathrm{BMD}$ or ${ }_{\mathrm{LS}} \mathrm{BMD}$ than female nonathletes, whilst male runners possessed but similar ${ }_{\mathrm{T}} \mathrm{BMD}$ and ${ }_{\mathrm{L}} \mathrm{BMD}$ compared to non-athletes. Male runners, however, also displayed lower BMD at the lumbar spine in comparison with non-athletes, which, hypothesised, may be due to the presence of reduced energy availability. Menstruation status and the number of sports completed in childhood did not appear to influence bone phenotypes, although large variability in BMD was observed in both the male and female runners and non-athletes, suggesting that other factors such as genetic variation, diet and types of loading influence BMD across the adult lifespan.

Supplementary Information The online version contains supplementary material available at https://doi.org/10.1007/s00421-021-04793-3.

Author contributions Conceptualisation: AJH, GKS, AGW; methodology: AJH, GKS, AGW; formal analysis and investigation: $\mathrm{AJH}$; writing —original draft preparation: $\mathrm{AJH}$; writing — review and editing: AJH, GKS, AGW, RME, PJH, CS, SHD, SJL; supervision: GKS, AGW, SHD, RME, CS, PJH. All authors read and approved the manuscript.

Funding The research was funded by Manchester Metropolitan University.

Data availability The data sets generated during and/or analysed during the current study are available from the corresponding author on reasonable request.

\section{Declarations}

Conflict of interest The authors have no relevant financial or non-financial interests to disclose.

Ethical approval The research study was approved by the appropriate Manchester Metropolitan University ethics committee and certify that the study was performed in accordance with the ethical standards as laid down in the 1964 Declaration of Helsinki and its later amendments or comparable ethical standards.

Consent to participate Informed consent was obtained from all individual participants included in the study.

Open Access This article is licensed under a Creative Commons Attribution 4.0 International License, which permits use, sharing, adaptation, distribution and reproduction in any medium or format, as long as you give appropriate credit to the original author(s) and the source, provide a link to the Creative Commons licence, and indicate if changes were made. The images or other third party material in this article are included in the article's Creative Commons licence, unless indicated otherwise in a credit line to the material. If material is not included in the article's Creative Commons licence and your intended use is not permitted by statutory regulation or exceeds the permitted use, you will need to obtain permission directly from the copyright holder. To view a copy of this licence, visit http://creativecommons.org/licenses/by/4.0/.

\section{References}

Andreoli A, Monteleone M, Van Loan M et al (2001) Effects of different sports on bone density and muscle mass in highly trained athletes. Med Sci Sport Exerc 33:507-511

Barrack MT, Rauh MJ, Nichols JF (2008) Prevalence of and traits associated with low BMD among female adolescent runners. Med Sci Sports Exerc 40:2015-2021

Bierhals IO, dos Santos VJ, Bielemann RM et al (2019) Associations between body mass index, body composition and bone density in young adults: findings from a southern Brazilian cohort. BMC Musculoskelet Disord 20:1-10

Bilanin JE, Blanchard MS, Russek-Cohen E (1989) Lower vertebral bone density in male long distance runners. Med Sci Sports Exerc 21:66-70

Blagrove RC, Brown N, Howatson G, Hayes PR (2017) Strength and conditioning habits of competitive distance runners. J Strength Cond Res 34:1392-1399

Brahm H, Ström H, Piehl-Aulin K et al (1997) Bone metabolism in endurance trained athletes: a comparison to population-based controls based on DXA, SXA, quantitative ultrasound, and biochemical markers. Calcif Tissue Int 61:448-454

Burrows M, Nevill AM, Bird S, Simpson D (2003) Physiological factors associated with low bone mineral density in female endurance runners. Br J Sports Med 37:67-71

Cappozzo A (1983) Force actions in the human trunk during running. J Sports Med Phys Fitness 23:14

Cheung AM, Frame H, Ho M et al (2016) Bone strength and management of postmenopausal fracture risk with antiresorptive therapies: considerations for women's health practice. Int J Womens Health 8:537

Cranney A, Jamal SA, Tsang JF et al (2007) Low bone mineral density and fracture burden in postmenopausal women. Can Med Assoc J 177:575-580 
Duncan CS, Blimkie CJ, Cowell CT et al (2002) Bone mineral density in adolescent female athletes: relationship to exercise type and muscle strength. Med Sci Sports Exerc 34:286-294

Farr JN, Lee VR, Blew RM et al (2011) Quantifying bone-relevant activity and its relation to bone strength in girls. Med Sci Sports Exerc 43:476

Felson DT, Zhang Y, Hannan MT, Anderson JJ (1993) Effects of weight and body mass index on bone mineral density in men and women: the Framingham study. J Bone Miner Res 8:567-573

Fredericson M, Chew K, Ngo J et al (2007) Regional bone mineral density in male athletes: a comparison of soccer players, runners, and controls. Br J Sports Med 41:664-668

Golchin MM, Heidari L, Ghaderian SMH, Akhavan-Niaki H (2016) Osteoporosis: a silent disease with complex genetic contribution. J Genet Genomics 43:49-61

Gorber SC, Schofield-Hurwitz S, Hardt J et al (2009) The accuracy of self-reported smoking: a systematic review of the relationship between self-reported and cotinine-assessed smoking status. Nicotine Tob Res 11:12-24

Gordon CM, Nelson LM (2003) Amenorrhea and bone health in adolescents and young women. Curr Opin Obstet Gynecol 15:377-384

Heikura IA, Uusitalo ALT, Stellingwerff T et al (2018) Low energy availability is difficult to assess but outcomes have large impact on bone injury rates in elite distance athletes. Int J Sport Nutr Exerc Metab 28:403-411

Herbert AJ, Williams AG, Hennis PJ et al (2019) The interactions of physical activity, exercise and genetics and their associations with bone mineral density: implications for injury risk in elite athletes. Eur J Appl Physiol 119:29-47

Hind K, Truscott JG, Evans JA (2006) Low lumbar spine bone mineral density in both male and female endurance runners. Bone 39:880-885

Hoch AZ, Pajewski NM, Moraski L et al (2009) Prevalence of the female athlete triad in high school athletes and sedentary students. Clin J Sport Med 19:421

Hsu Y-H, Kiel DP (2012) Genome-wide association studies of skeletal phenotypes: what we have learned and where we are headed. J Clin Endocrinol Metab 97:E1958-E1977

Kemmler W, Engelke K, Baumann H et al (2006) Bone status in elite male runners. Eur J Appl Physiol 96:78-85

Logue DM, Madigan SM, Melin A et al (2020) Low energy availability in athletes 2020: an updated narrative review of prevalence, risk, within-day energy balance, knowledge, and impact on sports performance. Nutrients 12:835

Loucks AB (2007) Low energy availability in the marathon and other endurance sports. Sport Med 37:348-352

Martin D, Sale C, Cooper SB, Elliott-Sale KJ (2018) Period prevalence and perceived side effects of hormonal contraceptive use and the menstrual cycle in elite athletes. Int J Sports Physiol Perform 13:926-932

Mountjoy M, Sundgot-Borgen JK, Burke LM et al (2018) IOC consensus statement on relative energy deficiency in sport (RED-S): 2018 update. Br J Sport Med 52:687-697

Nakashima T, Hayashi M, Fukunaga T et al (2011) Evidence for osteocyte regulation of bone homeostasis through RANKL expression. Nat Med 17:1231
Nevill AM, Burrows M, Holder RL et al (2003) Does lower-body BMD develop at the expense of upper-body BMD in female runners? Med Sci Sports Exerc 35:1733-1739

Papageorgiou M, Dolan E, Elliott-Sale KJ, Sale C (2018) Reduced energy availability: implications for bone health in physically active populations. Eur J Nutr 57:847-859

Pluijm SMF, Visser M, Smit JH et al (2001) Determinants of bone mineral density in older men and women: body composition as mediator. J Bone Miner Res 16:2142-2151

Pollock N, Grogan C, Perry M et al (2010) Bone-mineral density and other features of the female athlete triad in elite endurance runners: a longitudinal and cross-sectional observational study. Int J Sport Nutr Exerc Metab 20:418-426

Prince SA, Adamo KB, Hamel ME et al (2008) A comparison of direct versus self-report measures for assessing physical activity in adults: a systematic review. Int J Behav Nutr Phys Act 5:56

Ralston SH, Uitterlinden AG (2010) Genetics of osteoporosis. Endocr Rev 31:629-662

Scofield KL, Hecht S (2012) Bone health in endurance athletes: runners, cyclists, and swimmers. Curr Sports Med Rep 11:328-334

Small CM, Manatunga AK, Marcus M (2007) Validity of self-reported menstrual cycle length. Ann Epidemiol 17:163-170

Stewart AD, Hannan J (2000) Total and regional bone density in male runners, cyclists, and controls. Med Sci Sports Exerc 32:1373-1377

Swann C, Moran A, Piggott D (2015) Defining elite athletes: issues in the study of expert performance in sport psychology. Psychol Sport Exerc 16:3-14

Tveit M, Rosengren BE, Nilsson JÅ et al (2013) Bone mass following physical activity in young years: a mean 39-year prospective controlled study in men. Osteoporos Int 24:1389-1397

Varley I, Stebbings G, Williams AG et al (2021) An investigation into the association of bone characteristics and body composition with stress fracture in athletes. J Sports Med Phys Fitness. https://doi. org/10.23736/S0022-4707.21.11871-7

Velez NF, Zhang A, Stone B et al (2008) The effect of moderate impact exercise on skeletal integrity in master athletes. Osteoporos Int 19:1457-1464

Ward KA, Ashby RL, Roberts SA et al (2007) UK reference data for the Hologic QDR Discovery dual-energy x ray absorptiometry scanner in healthy children and young adults aged 6-17 years. Arch Dis Child 92:53-59

Weaver CM, Gordon CM, Janz KF et al (2016) The National Osteoporosis Foundation's position statement on peak bone mass development and lifestyle factors: a systematic review and implementation recommendations. Osteoporos Int 27:1281-1386

Weeks BK, Beck BR (2008) The BPAQ: a bone-specific physical activity assessment instrument. Osteoporos Int 19:1567-1577

Publisher's Note Springer Nature remains neutral with regard to jurisdictional claims in published maps and institutional affiliations. 